\title{
Short communication: Diversity of species and transmission of antimicrobial resistance among Staphylococcus spp. isolated from goat milk
}

\author{
Viviane Coimbra-e-Souza, ${ }^{1 *}$ Ciro C. Rossi, ${ }^{1 *}$ Luana J. Jesus-de Freitas, ${ }^{1}$ Maria Aparecida V. P. Brito, ${ }^{2}$ \\ Marinella S. Laport, ${ }^{1}$ and Marcia Giambiagi-deMarval ${ }^{1} \dagger$ \\ ${ }^{1}$ Instituto de Microbiologia Paulo de Góes, Universidade Federal do Rio de Janeiro, 21941-590, Rio de Janeiro, Brazil \\ ${ }^{2}$ Embrapa Gado de Leite, 36038-330, Juiz de Fora, MG, Brazil
}

\section{ABSTRACT}

The increasing production of goat milk and its derivatives is affected by the occurrence of intramammary infections, which are highly associated with the presence of Staphylococcus species, including some with zoonotic potential. Staphylococci in general can exchange mobile genetic elements, a process that may be facilitated by the isolate's capacity of forming biofilms. In this study we identified, to the species level, Staphylococcus isolated from goat milk samples by MALDI-TOF and confirmed the identification by sequencing housekeeping genes (rrs and tuf). Eight species were identified, more than half being either Staphylococcus epidermidis or Staphylococcus lugdunensis. The isolates were shown by pulsed-field gel electrophoresis to be genetically diverse between the studied herds. Resistance to ampicillin and penicillin was widespread, and 2 Staph. epidermidis isolates contained the methicillin-resistance gene mecA. Most of the isolates that were resistant to at least 1 of the 13 antimicrobials tested harbored plasmids, one of which was demonstrated to be conjugative, being transferred from a Staph. epidermidis to a Staphylococcus aureus strain. Biofilm formation was observed in almost every isolate, which may contribute to their capacity of exchanging antimicrobial resistance genes in addition to acting as a physical barrier to the access of drugs. Our results showed that antimicrobial resistance among goat staphylococci may be emerging in a process facilitated by the exchange of mobile genetic elements between the bacteria and the establishment of biofilms, which calls for careful monitoring and more effective control therapies.

Key words: goat intramammary infection, antimicrobial resistance, horizontal gene transfer, biofilm, staphylococci

Received October 1, 2018.

Accepted February 6, 2019.

*These authors contributed equally to this work.

†Corresponding author: marciagm@micro.ufrj.br

\section{Short Communication}

The consumption of goat milk and its derivatives is boosted by their greater digestibility and lower allergenicity compared with cow milk products (García et al., 2014). Although goat milk accounts for only about 3\% of global milk production, the aforementioned benefits of goat milk and the selection of highly productive dairy breeds are responsible for the growth of the industry, which goes through expressive $4.1 \%$ annual growth in developing countries (FAO, 2013; OECD-FAO, 2017). In Brazil, the annual 3.5\% growth of the goat dairy industry is driven by the support and subsidy of federal government programs (Jung and Júnior, 2016).

Several factors can affect milk productivity, such as the animals' genetic potential, nutrition, and feeding practices, but proper management to avoid IMI is crucial to ensure higher yield and quality of the final product (Goetsch et al., 2011). Intramammary infections may lead to mastitis, one of the most frequent diseases in dairy herds, which is usually accompanied by abnormal changes in the physical, chemical, and bacteriological features of milk. The extensive losses due to this disease in herds are associated with a decrease in milk quality and production, expenses with drugs and veterinary care, and culling of animals (Peixoto et al., 2010).

Bacteria of the Staphylococcus genus can account for 60 to $96 \%$ of the microorganisms causing goat mastitis, Staphylococcus epidermidis being the predominant species. Given the zoonotic potential of Staph. epidermidis and Staphylococcus aureus, with the focus on these species, other species isolated from goats with mastitis may be overlooked or not properly identified (Peixoto et al., 2010; Goetsch et al., 2011). However, studies have shown that different species of Staphylococcus, considered to be less pathogenic, are able to exchange genetic material among themselves, and the transfer of antimicrobial resistance genes from harmless species to potentially pathogenic ones represents a threat to their hosts (Otto, 2013a; Rossi et al., 2017). This transfer is facilitated by the strains' capacity of forming biofilms, which provide an environment of high cellular density, 
availability of mobile DNA, and increased natural capacity to exchange genetic elements (Madsen et al., 2012). Thus, this work aimed to identify Staphylococcus species from goat milk samples collected from 3 herds as well as evaluate their genetic diversity, the profile of antimicrobial resistance, biofilm formation, presence of mobile genetic elements, and their transfer potential.

Milk samples were aseptically collected from both halves (composite milk) of lactating goats of Toggenburg breed (1 herd, $\mathrm{n}=131)$ and Saanen breed (2 herds, $\mathrm{n}=45$ and 20). All animals were considered to be clinically healthy as they did not present signs of clinical mastitis or udder inflammation, they were not under treatment with antibiotics and the initial streams of foremilk (which were discarded) did not present any organoleptic alterations. After predipping disinfection, teat ends were cleaned with ethanol $70 \%$. Goats were hand milked and produced an average of 2.0 to $2.5 \mathrm{~L}$ of milk/d. Approximately $5 \mathrm{~mL}$ of milk was collected from each udder half and pooled in a sterile tube. Samples were kept at $4^{\circ} \mathrm{C}$ and taken to the laboratory for processing, and the microbiological culture was performed within $24 \mathrm{~h}$ of sampling according to National Mastitis Council (2004) recommendations. A volume of $10 \mu \mathrm{L}$ of each sample was spread on blood agar plates. Plates were examined after 24 and $48 \mathrm{~h}$ of aerobic incubation at $37^{\circ} \mathrm{C}$. The following criteria were evaluated: colony morphology, type of hemolysis, Gram stain, catalase activity, and coagulase activity on rabbit plasma (Bio-Rad, Hercules, CA). The gram-positive, catalasepositive, and coagulase-negative cocci were identified as coagulase-negative staphylococci, whereas the grampositive, catalase-positive, and coagulase-positive cocci were identified as coagulase-positive staphylococci. Staphylococcus colonies were isolated on 51 of the 196 goat milk samples. All isolates were inoculated in brain heart infusion (BD, Franklin Lakes, NJ) and incubated at $37^{\circ} \mathrm{C}$ for $18 \mathrm{~h}$ before every test. Staphylococci were considered to be agents of IMI if 5 or more colonies were growing in pure culture on the blood agar plates (National Mastitis Council, 2004).

Isolates were identified to species level by the combination of 3 analytical approaches to ensure proper identification. First, the differentiation of protein profiles of the bacterial cultures was analyzed in triplicate by MALDI-TOF/MS. Extraction was performed as suggested by Sauer et al. (2008), with modifications: pure colonies were spotted in triplicate on a polished steel target plate, dried, and overlaid with $1 \mu \mathrm{L}$ of formic acid (Sigma-Aldrich, St. Louis, MO). After drying again, all spots were overlaid with $1 \mu \mathrm{L}$ of matrix, a solution of $\alpha$-cyano-4-hydroxycinnamic acid (Sigma-Aldrich) prepared in 50\% acetonitrile (Sigma-Aldrich) and 2.5\% trifluoroacetic acid (Sigma-Aldrich). After complete drying, the plate was inserted into the Bruker Microflex LT MALDI-TOF system (Bruker, Billerica, MA). Mass spectral data were collected within the mass/charge ratio $(m / z)$ range of 2,000 to 20,000 , and data were acquired and analyzed using FlexControl software 3.3 and the Biotyper database version 3.1.2. (Bruker). As suggested by the software's manufacturer, the score cutoff of $\geq 2.000$ was considered a secure genus identification and probable species identification. The MALDI-TOF results were confirmed by sequencing the rrs (16S rRNA) and tuf genes. Genomic DNA was isolated from the bacterial isolates by the guanidinium thiocyanate extraction method (Pitcher et al., 1989). The rrs gene was amplified with the universal primers 9f/1492r (Weisburg et al., 1991), and the tuf gene was amplified with the primers tufF/tufR (Heikens et al., 2005) with the GoTaq G2 Green Master Mix (Promega, Madison, WI) following the manufacturer's protocols and PCR conditions according to the cited reference. The PCR fragments were purified with the Wizard SV Gel and PCR Clean-Up System (Promega) and sequenced on the Illumina MiSeq platform (Illumina, San Diego, CA). Eight Staphylococcus species were identified (Table 1). Most isolates $(15 / 51,29 \%)$ were Staph. epidermidis, followed by Staph. lugdunensis $(11 / 51,22 \%)$, Staph. aureus $(7 / 51,14 \%)$, Staph. simulans (6/51, 12\%), Staph. xylosus (4/51, 8\%), Staph. caprae (3/51, 6\%), Staph. capitis $(2 / 51,4 \%)$, and Staph. pausteri $(1 / 51,2 \%)$. Only 2 isolates $(3 \%)$ did not produce reliable MALDITOF or coincident sequencing results, being identified as Staphylococcus spp. (Table 1).

Isolates of the same species were shown to be genetically diverse by their chromosomal restriction patterns produced by the $S m a \mathrm{I}$ enzyme (Appendix Figure A1), separated by pulsed-field gel electrophoresis, following the protocols suggested by Nunes et al. (2005). Clustering analysis of the pulsed-field gel electrophoresis products was performed using Bionumerics 6.0 software (Applied Maths, Sint-Martens-Latem, Belgium) with the unweighted pair-group method with arithmetic mean (UPGMA) algorithm and the Jaccard coefficient. Isolates were clustered in several pulsotypes (Appendix Figure A1). The genetic variability among the isolates of different farms is most likely due to the nature of the goat milk production in Brazil, which is typically performed by small independent properties (Marcondes et al., 2017), which avoids the exchange of bacteria between them. On the other hand, the occurrence of similar pulsotypes on the same farm indicates transmission between the animals.

The antimicrobial susceptibility of all isolates was tested by the disk diffusion method against the follow- 
ing antimicrobials (Cecon, São Paulo, Brazil): ampicillin $(10 \mu \mathrm{g})$, cefoxitin $(30 \mu \mathrm{g})$, ciprofloxacin $(5 \mu \mathrm{g})$, clindamycin $(2 \mu \mathrm{g})$, erythromycin $(15 \mu \mathrm{g})$, gentamicin $(10 \mu \mathrm{g})$, mupirocin $(5$ and $200 \mu \mathrm{g})$, oxacillin $(1 \mu \mathrm{g})$, penicillin G (10 UI), rifampicin (5 $\mu \mathrm{g})$, trimethoprimsulfamethoxazole $(1.25 / 23.75 \mu \mathrm{g})$, tetracycline $(30 \mu \mathrm{g})$, and vancomycin $(30 \mu \mathrm{g})$. All tests were performed using Müller-Hinton agar (Oxoid, Basingstoke, UK) according to the Clinical and Laboratory Standards Institute guidelines (CLSI, 2016a). Staphylococcus aureus ATCC 25923 was included in each batch of test as a quality control. Inhibition zone interpretative criteria for anti- microbials were determined using human data (CLSI, $2016 \mathrm{~b})$ when not available for veterinary practice.

More than half $(28 / 51,55 \%)$ of the isolates were resistant to at least 1 of the 13 antimicrobials evaluated (Table1). Resistance to penicillin and ampicillin was observed in $39 \%(20 / 51)$ of isolates, which is consistent with the fact that these antimicrobials have been widely used in veterinary practice, including to treat mastitis caused by gram-positive bacteria (Silva et al., 2012). All the isolates were sensitive to rifampicin, vancomycin, oxacillin, and mupirocin. Two Staph. epidermidis isolates (8389 and 8398) were resistant to

Table 1. Characterization of the Staphylococcus spp. isolated from the milk of goats with mastitis used in this work ${ }^{1}$

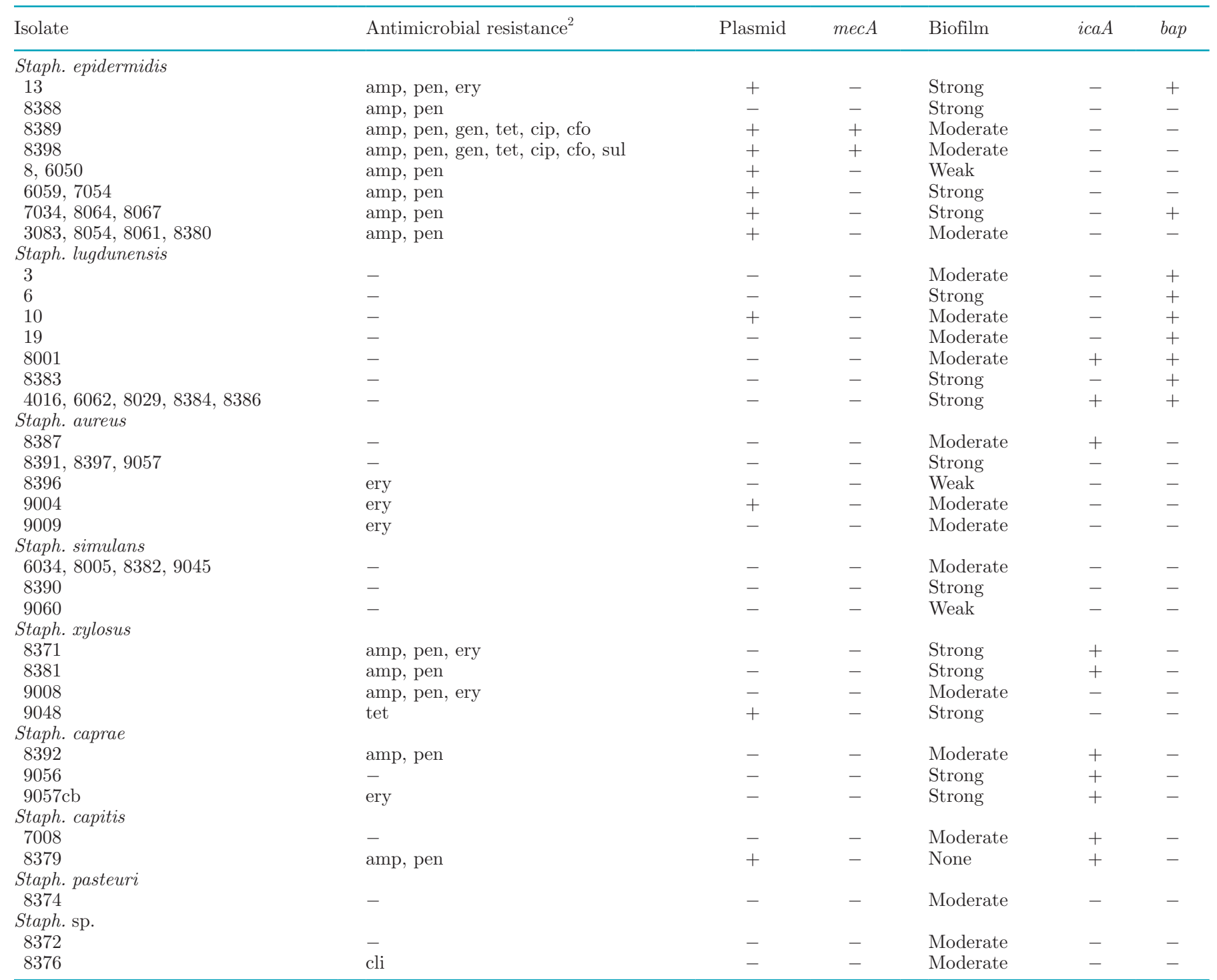

${ }^{1}+$ denotes the presence of plasmids or genes investigated; - denotes their absence as well as no resistance to the antimicrobials tested.

${ }^{2}$ Antimicrobials: ampicillin (amp), cefoxitin (cfo), ciprofloxacin (cip), clindamycin (cli), erythromycin (ery), gentamicin (gen), penicillin G (pen), trimethoprim-sulfamethoxazole (sul), tetracycline (tet). 

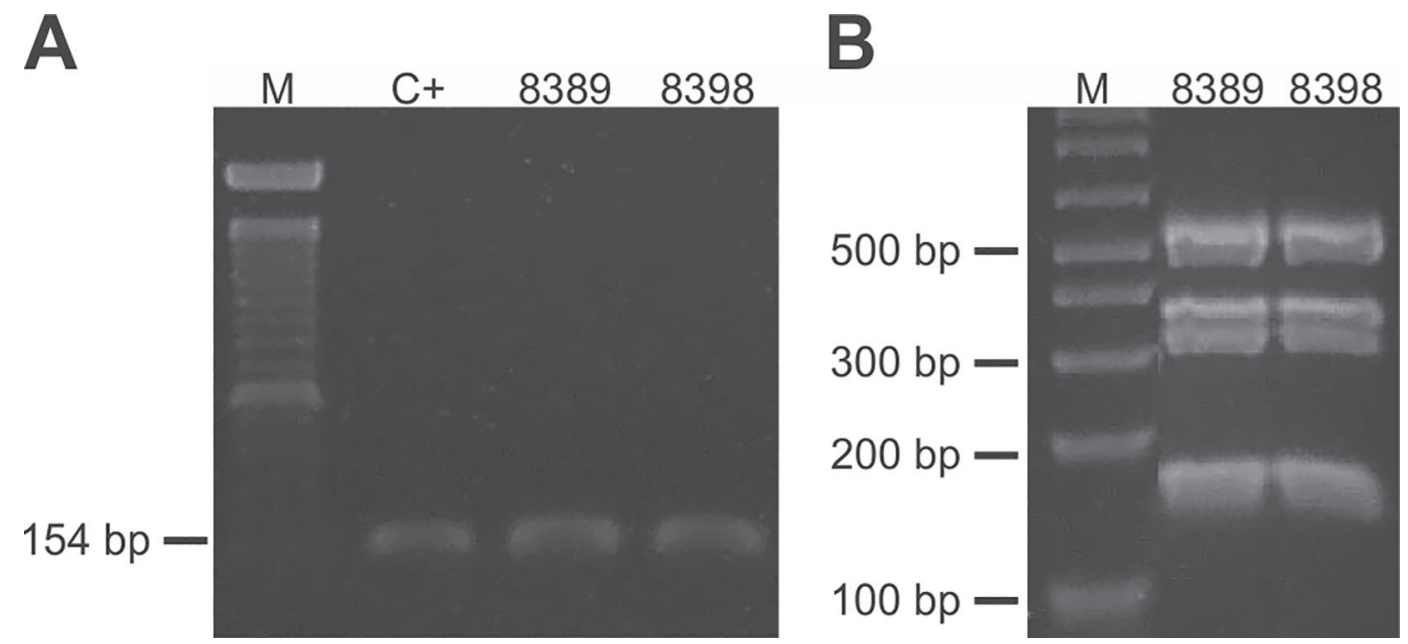

Figure 1. Characterization of methicillin resistance in the 2 cefoxitin-resistant isolates identified in this work. (A) Detection of the mecA gene by PCR and (B) classification of the SCCmec type by multiplex PCR in the Staphylococcus epidermidis 8389 and 8398 isolates. M = molecular weight marker; $\mathrm{C}+=$ positive control, Staphylococcus haemolyticus isolate MD2.

multiple drugs and capable of growing in the presence of penicillin, ampicillin, gentamicin, tetracycline, ciprofloxacin, and cefoxitin. Isolate 8398 was also resistant to trimethoprim-sulfamethoxazole.

All isolates were assessed for the presence of the methicillin-resistance gene mecA by PCR with the primers MRS1/MRS2 (Del Vecchio et al., 1995) using the GoTaq G2 Green Master Mix (Promega) following the manufacturer's protocols and PCR conditions according to the cited reference. The Staphylococcus haemolyticus isolate MD2 (Rossi et al., 2016) was used as a positive control for the reaction. The mecA gene was detected in Staph. epidermidis 8398 and 8389 (Table 1 and Figure 1A). These were the only isolates resistant to cefoxitin, which is indicative of the presence of $m e c A$ (CLSI, 2016b).

The determination of the type of staphylococcal cassette chromosome mec (SCCmec) present in isolates 8398 and 8389 was performed by the multiplex PCR suggested by Milheiriço et al. (2007). Although both presented the same pattern of 4 -fragments amplification (Figure 1B), the profile obtained did not match any of the previously characterized (Milheiriço et al., 2007). Although methicillin-resistant Staphylococcus aureus has been isolated from goats with mastitis (Obaidat et al., 2018), this is, as we are aware, the first report of methicillin-resistant Staph. epidermidis obtained from goat milk samples.

To correlate antimicrobial resistance profiles with the presence of mobile genetic elements, all isolates were submitted to plasmid extraction using a lysis buffer containing lysostaphin (Sigma-Aldrich, $10 \mu \mathrm{g} / \mathrm{mL}$ ) and pronase (Sigma-Aldrich, $1 \mathrm{mg} / \mathrm{mL}$ ), followed by treatment with SDS $2 \%$ at $65^{\circ} \mathrm{C}$ for 5 min, protein precipitation with $0.4 \mathrm{M} \mathrm{KCl}$, and DNA precipitation with ethanol, as previously described (Giambiagi-Marval et al., 1990).

Most $(18 / 26,69 \%)$ of the isolates that presented resistance to at least 1 antimicrobial tested harbored plasmids (Table 1). On the other hand, only 1 (Staph. xylosus 9048) from the 25 isolates that did not present any resistance showed plasmidial forms. It is then very likely that much of the antimicrobial resistance observed is due to the presence of genes located within mobile genetic elements.

The multidrug-resistant isolates Staph. epidermidis 8389 and 8398 were selected to evaluate the transferability of the plasmid through conjugation experiments using Staph. aureus RN2677 as the recipient strain. We selected the resistance to gentamicin, which is well documented as a transferrable resistance among staphylococci (Ramsay et al., 2016), as the molecular marker of the transfer. Conjugations were performed using overnight filter matings with $10^{9} \mathrm{cfu}$ of both donor and recipient cells (Projan and Archer, 1989). Transconjugants were selected on brain heart infusion agar containing gentamicin $(10 \mu \mathrm{g} / \mathrm{mL})$, novobiocin $(5$ $\mu \mathrm{g} / \mathrm{mL})$, and rifampicin $(5 \mu \mathrm{g} / \mathrm{mL})$. Only Staph. epidermidis 8398 successfully transferred a copy of its plasmid to Staph. aureus RN2677, which acquired resistance to gentamicin, with a conjugation frequency of $2.7 \times 10^{8}$ per donor cells.

The transfer of plasmids has been demonstrated for different species of staphylococci (Otto, 2013a; Rossi et al., 2016), including between staphylococci isolated from domestic animals and isolates from human beings 
(Rossi et al., 2017). Our results highlight the fact that bacteria of the Staphylococcus genus act as antimicrobial resistance gene reservoirs and are able to transfer mobile genetic elements among themselves, thus increasing their capacity to resist antimicrobial therapy. Even though the plasmid from isolate Staph. epidermidis 8389 was not transferred to Staph. aureus, it was reported that plasmids characterized as nonmobilizable may be horizontally transferred in biofilms (Madsen et al., 2012).

All isolates were then tested for biofilm production in 96-well microplates, following the crystal violet staining method. Isolates were classified as nonproducers or weak, moderate, or strong biofilm producers depending on how strong their optical density at $570 \mathrm{~nm}$ reading was (equal or lower, up to twice, up to 4 times, or higher than 4 times, respectively) compared with the negative control (Stepanović et al., 2007). The detection of the genes icaA and bap, related to biofilm production, was performed by PCR with the primers ICAAF/ICAAR and BAP2F/BAP2R (Potter et al., 2009) with the GoTaq G2 Green Master Mix (Promega), following the manufacturer's protocols and PCR parameters according to the cited reference.

Biofilm production was an almost universal feature among the Staphylococcus isolates studied in this work (Table 1 ), as only 1 isolate was not capable of adherence. Therefore, $98 \%(50 / 51)$ of the isolates formed biofilms, of which $8 \%(4 / 50)$ were weakly adhered to the surface tested, $46 \%(23 / 50)$ were moderately adhered, and the other $46 \%$ formed strongly attached biofilms. There did not seem to be a direct correlation between the occurrence of the $i c a A$ and bap genes and how strong the biofilm was attached to the surface in the isolates tested (Table 1). Although isolates such as Staph. lugdunensis 4016, 6062, 8029, 8384, and 8386 formed strong biofilms and had both icaA and bap genes, these genes were not detected in the also strong biofilm producers Staph. aureus 8391, 8397, and 9057. In addition the non-biofilm-producing Staph. $\mathrm{ca}$ pitis 8379 was positive for the icaA gene. Overall, $27 \%$ $(14 / 51)$ of the isolates were positive for $i c a A$ and $29 \%$ $(15 / 51)$ were positive for bap. It is probable that other factors may be involved with biofilm formation in these isolates, such as different surface-anchored proteins that bind to host matrix proteins, collectively called microbial surface components recognizing adhesive matrix molecules, accumulation-associated proteins, and polysaccharide intercellular adhesin (Otto, 2013b). The importance of biofilms in the exchange of antimicrobial resistance genes and as physical barriers to the access of drugs to the target cells is well known (Madsen et al., 2012), making it an important target for therapies aiming to control the occurrence and dissemination of goat mastitis.

Our work shows that several species of the Staphylococcus genus can be isolated from goat milk, potentially leading to infectious processes such as mastitis. The antimicrobial resistance phenotypes presented by them seem to be associated with mobile genetic elements, which can be transferred between different staphylococcal species, a process that is likely facilitated by the isolate's capacity to form biofilms.

\section{ACKNOWLEDGMENTS}

The authors are grateful for the financial support from Fundação de Amparo à Pesquisa do Estado do Rio de Janeiro (FAPERJ, Rio de Janeiro, Brazil; grants E-26/203.037/2016 and E-26/201.451/2014), Conselho Nacional de Desenvolvimento Científico e Tecnológico (CNPq, Brasília, Brazil; grants 304.506/2014-1 and 304.318/2013-2), and Coordenação de Aperfeiçoamento de Pessoal de Nível Superior Programa de Excelência Acadêmica-Finance Code 001 (CAPES ProEx, Brasília, Brazil; grant 23038.002486/2018-26).

\section{REFERENCES}

CLSI (Clinical and Laboratory Standards Institute). 2016a. Performance standards for antimicrobial disk and dilution susceptibility tests for bacteria isolated from animals. 4th ed. Document VET01A4. Clinical and Laboratory Standards Institute, Wayne, PA.

CLSI (Clinical and Laboratory Standards Institute). 2016b. Performance standards for antimicrobial susceptibility testing. 26th ed. Document M100S. Clinical and Laboratory Standards Institute, Wayne, PA.

Del Vecchio, V. G., J. M. Petroziello, M. J. Gress, F. K. McCleskey, G. P. Melcher, H. K. Crouch, and J. R. Lupski. 1995. Molecular genotyping of methicillin-resistant Staphylococcus aureus via fluorophore-enhanced repetitive-sequence PCR. J. Clin. Microbiol. 33:2141-2144.

FAO. 2013. Milk and Dairy Products in Human Nutrition. Food and Agriculture Organization of the United Nations, Rome, Italy.

García, C., S. Rovira, K. Boutoial, and M. B. López. 2014. Improvements in goat milk quality: A review. Small Rumin. Res. 121:51-57.

Giambiagi-Marval, M., M. A. Mafra, E. G. C. Penido, and M. C. F. Bastos. 1990. Distinct groups of plasmids correlated with bacteriocin production in Staphylococcus aureus. J. Gen. Microbiol. 136:1591-1599.

Goetsch, A. L., S. S. Zeng, and T. A. Gipson. 2011. Factors affecting goat milk production and quality. Small Rumin. Res. 101:55-63.

Heikens, E., A. Fleer, A. Paauw, A. Florijn, and A. C. Fluit. 2005. Comparison of genotypic and phenotypic methods for species-level identification of clinical isolates of coagulase-negative staphylococci. J. Clin. Microbiol. 43:2286-2290.

Jung, C. F., and A. A. M. Júnior. 2016. Produção leiteira no Brasil e características da bovinocultura leiteira no Rio Grande do Sul. Agora 19:34-47.

Madsen, J. S., M. Burmolle, L. H. Hansen, and S. J. Sorensen. 2012 The interconnection between biofilm formation and horizontal gene transfer. FEMS Immunol. Med. Microbiol. 65:183-195.

Marcondes, M. I., V. L. N. Brandão, G. A. T. Ferreira, and A. L. Silva. 2017. Impact of farm size on milk quality in the Brazilian 
dairy industry according to the seasons of the year. Cienc. Rural 47:e20161004.

Milheiriço, C., D. C. Oliveira, and H. de Lencastre. 2007. Update to the multiplex PCR strategy for assignment of mec element types in Staphylococcus aureus. Antimicrob. Agents Chemother. 51:3374-3377.

National Mastitis Council. 2004. Microbiological Procedures for the Diagnosis of Bovine Udder Infection and Determination of Milk Quality. 4th ed. National Mastitis Council, Verona, WI.

Nunes, A. P., L. M. Teixeira, C. C. Bastos, M. G. Silva, R. B. Ferreira, L. S. Fonseca, and K. R. Santos. 2005. Genomic characterization of oxacillin-resistant Staphylococcus epidermidis and Staphylococcus haemolyticus isolated from Brazilian medical centres. J. Hosp. Infect. 59:19-26.

Obaidat, M. M., A. E. Bani Salman, and A. A. Roess. 2018. High prevalence and antimicrobial resistance of mecA Staphylococcus aureus in dairy cattle, sheep, and goat bulk tank milk in Jordan. Trop. Anim. Health Prod. 50:405-412.

OECD-FAO (Organisation for Economic Co-operation and Development-Food and Agriculture Organization of the United Nations. 2017. OECD-FAO Agricultural Outlook 2017-2026. OECD, Paris, France.

Otto, M. 2013a. Coagulase-negative staphylococci as reservoirs of genes facilitating MRSA infection: Staphylococcal commensal species such as Staphylococcus epidermidis are being recognized as important sources of genes promoting MRSA colonization and virulence. BioEssays 35:4-11.

Otto, M. 2013b. Staphylococcal infections: Mechanisms of biofilm maturation and detachment as critical determinants of pathogenicity. Annu. Rev. Med. 64:175-188.

Peixoto, R. M., R. A. Mota, and M. M. Costa. 2010. Small ruminant mastitis in Brazil. Pesqui. Vet. Bras. 30:754-762.

Pitcher, D. G., N. A. Saunders, and R. J. Owen. 1989. Rapid extraction of bacterial genomic DNA with guanidium thiocyanate. Lett. Appl. Microbiol. 8:151-156.

Potter, A., H. Ceotto, M. Giambiagi-Demarval, K. R. dos Santos, I. F. Nes, and C. Bastos Mdo. 2009. The gene bap, involved in biofilm production, is present in Staphylococcus spp. strains from nosocomial infections. J. Microbiol. 47:319-326.

Projan, S. J., and G. L. Archer. 1989. Mobilization of the relaxable Staphylococcus aureus plasmid $\mathrm{pC} 221$ by the conjugative plasmid pGO1 involves three pC221 loci. J. Bacteriol. 171:1841-1845.

Ramsay, J. P., S. M. Kwong, R. J. Murphy, K. Yui Eto, K. J. Price, Q. T. Nguyen, F. G. O'Brien, W. B. Grubb, G. W. Coombs, and N. Firth. 2016. An updated view of plasmid conjugation and mobilization in Staphylococcus. Mob. Genet. Elements 6:e1208317.

Rossi, C. C., N. C. Ferreira, M. L. Coelho, R. P. Schuenck, C. Bastos Mdo, and M. Giambiagi-deMarval. 2016. Transfer of mupirocin resistance from Staphylococcus haemolyticus clinical strains to Staphylococcus aureus through conjugative and mobilizable plasmids. FEMS Microbiol. Lett. 363:fnw121.

Rossi, C. C., T. Souza-Silva, A. V. Araujo-Alves, and M. GiambiagideMarval. 2017. CRISPR-Cas systems features and the gene-reservoir role of coagulase-negative staphylococci. Front. Microbiol. $8: 1545$.

Sauer, S., A. Freiwald, T. Maier, M. Kube, R. Reinhardt, M. Kostrzewa, and K. Geider. 2008. Classification and identification of bacteria by mass spectrometry and computational analysis. PLoS One 3:e2843.

Silva, E. R., A. M. G. Pereira, W. S. Moraes, K. R. Santoro, and T. R. M. Silva. 2012. In vitro antimicrobial susceptibility of Staphylococcus aureus isolated from bovine subclinical mastitis. Rev. Bras. Saúde Prod. Anim. 13:701-711.

Stepanović, S., D. Vukovic, V. Hola, G. Di Bonaventura, S. Djukic, I. Cirkovic, and F. Ruzicka. 2007. Quantification of biofilm in microtiter plates: Overview of testing conditions and practical recommendations for assessment of biofilm production by staphylococci. APMIS 115:891-899.

Weisburg, W. G., S. M. Barns, D. A. Pelletier, and D. J. Lane. 1991. $16 \mathrm{~S}$ ribosomal DNA amplification for phylogenetic study. J. Bacteriol. 173:697-703. 


\section{APPENDIX}

A) S. lugdunensis

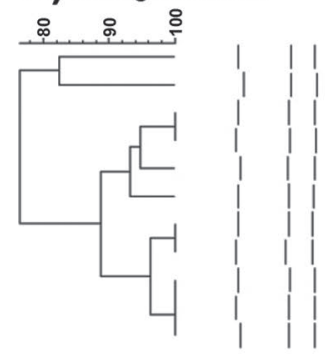

strain clone herd

$\begin{array}{lll}19 & \text { A1 } & 3 \\ 10 & \text { A2 } & 3 \\ 8383 & \text { A1 } & 1 \\ 8386 & \text { B1 } & 1 \\ 8384 & \text { B1 } & 1 \\ 4016 & \text { B3 } & 2 \\ 8001 & \text { B4 } & 2 \\ 8029 & \text { B4 } & 2 \\ 6062 & \text { B5 } & 2 \\ 6 & \text { B5 } & 3 \\ 3 & \text { B5 } & 3\end{array}$

C) S. aureus 更

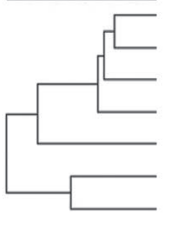

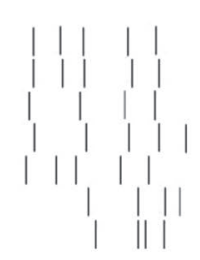

strain clone herd

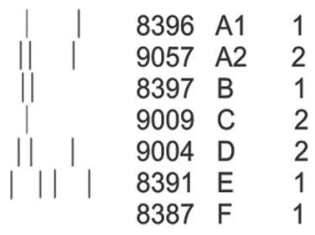

B) S. epidermidis

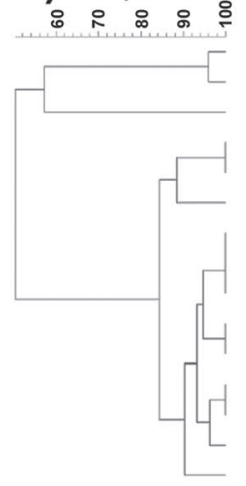

strain clone herd

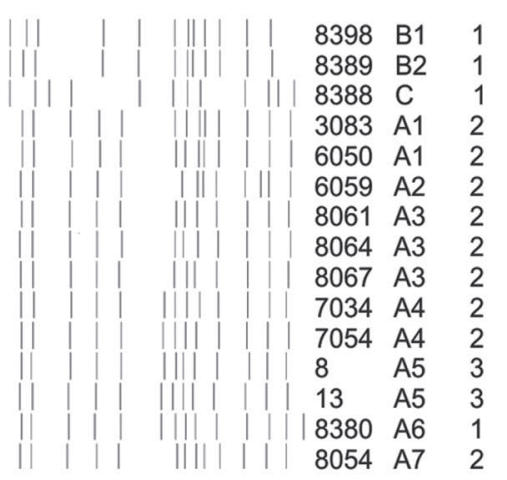

D) S. xylosus

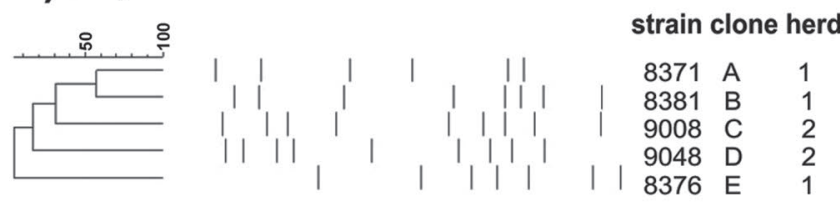

F) S. caprae

\% : : :
E) S. simulans
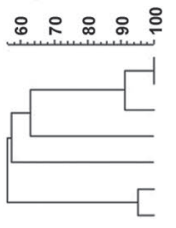

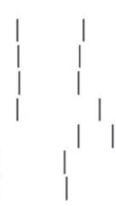

strain clone herd

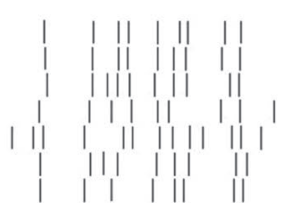

6034 A1 2

$\begin{array}{lll}6034 & \text { A1 } & 2 \\ 9045 & \text { A1 } & 2\end{array}$ 8005 A2

8390 B
8382 C 1 strain clone herd

9056 A 2 $9057 \mathrm{cb}$ B 2 $\begin{array}{lll}8392 & \text { C } & 1 \\ 7008 & D & 2\end{array}$

Figure A1. Dendrograms built with the clustering displayed by the SmaI restriction fragments separated by pulsed-field gel electrophoresis

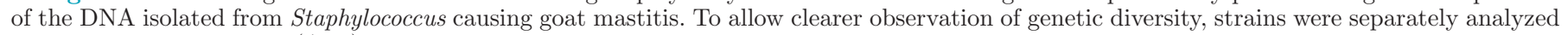
according to their species $(\mathrm{A}-\mathrm{F})$. 